\title{
SIMULATING POROSITY AND PERMEABILITY OF THE NUCLEAR MAGNETIC RESONANCE (NMR) LOG IN CARBONATE RESERVOIRS OF CAMPOS BASIN, SOUTHEASTERN BRAZIL, USING CONVENTIONAL LOGS AND ARTIFICIAL INTELLIGENCE APPROACHES
}

\author{
Antonio Abel González Carrasquilla ${ }^{1}$ and Victor Hugo Tapia Briones²
}

\begin{abstract}
We examined, in this study, the artificial intelligence techniques ability in deriving parameters of the Nuclear Magnetic Resonance log, starting from conventional logs. To perform this, it was applied Fuzzy Logic and Artificial Neural Network techniques separately, forming independent schemes. On the other hand, Simple Average and Genetic Algorithm approaches were used to assign weighting factors to Fuzzy Logic and Artificial Neural Network estimates, with the objective to optimize the individual contributions of each one. To do this, the methodology used conventional well logs, that is, gamma ray, resistivity, neutron porosity, density and sonic logs. The wells are in an Albian carbonate reservoir in Campos Basin, Southeastern Brazil. The responses were compared with the Schlumberger free fluid porosity and the lateral permeability, both derived from Nuclear Magnetic Resonance log in the same wells. The results indicate that Artificial Neural Network performed better when compared with Fuzzy Logic, but this last was essential in the success of Simple Average and Genetic Algorithm estimates, which presented better results than these techniques individually. However, each approach showed a good fit with the parameters of the Nuclear Magnetic Resonance log, confirming the utility of the present methodology, in the case when there are only conventional logs, in the studied wells.
\end{abstract}

Keywords: geophysical well logging, Nuclear Magnetic Resonance, intelligent systems, Fuzzy Logic, Artificial Neural Network, Genetic Algorithm.

RESUMO. Examinamos, neste estudo, a habilidade das técnicas de inteligência artificial na determinação de parâmetros do perfil da Ressonância Magnética Nuclear, a partir de perfis convencionais. Para tanto, foram aplicadas, separadamente, as técnicas da Lógica Fuzzy e da Rede Neural Artificial formando esquemas independentes. Por outro lado, as abordagens da Média Simples e do Algoritmo Genético foram utilizadas para atribuir os fatores de ponderação às estimativas de Lógica Fuzzy e Rede Neural Artificial, com o objetivo de otimizar as contribuições individuais de cada uma. Com esse objetivo, a metodologia utilizou os perfis convencionais de dois poços, ou seja, raios gama, resistividade, porosidade neutrônica, densidade e sônico. Os poços pertencem a um reservatório carbonático Albiano na Bacia de Campos, Sudeste do Brasil. As respostas foram comparadas com a porosidade do fluido livre e a permeabilidade lateral da Schlumberger, ambas derivadas do perfil da Ressonância Magnética Nuclear, nos mesmos poços. Os resultados indicam que a Rede Neural Artificial apresentou melhor desempenho, quando comparada com a Lógica Fuzzy, mas esta última foi essencial para o sucesso das estimativas da Média Simples e do Algoritmo Genético, os quais apresentaram melhores resultados do que estas técnicas individualmente. No entanto, cada abordagem apresentou um bom ajuste com os parâmetros do perfil da Ressonância Magnética Nuclear, confirmando a utilidade dessa metodologia, no caso em que existem apenas perfis convencionais nos poços estudados.

Palavras-chave: perfis geofísicos de poços, Ressonância Magnética Nuclear, sistemas inteligentes, Lógica Fuzzy, Rede Neural Artificial, Algoritmo Genético.

\footnotetext{
${ }^{1}$ Universidade Estadual do Norte Fluminense Darcy Ribeiro (UENF), Laboratory of Engineering and Exploration of Petroleum (LENEP), Rodovia Amaral Peixoto, Km 163, Avenida Brennand, S/N, Imboacica, 27925-310, Macaé, RJ, Brazil - Phone: +55(22) 2765-6564. E-mail: abel@lenep.uenf.br

${ }^{2}$ Schlumberger Oil Services Ltd., Rua Internacional, 500, Granja dos Cavaleiros, 27930-075, Macaé, RJ, Brazil. Phone: +55(22) 2773-5151 - E-mail: hugotabri@gmail.com
} 


\section{INTRODUCTION}

In the characterization of a reservoir, the Nuclear Magnetic Resonance (NMR) log predicts petrophysical parameters of geological formations more effectively than the conventional well logs, allowing a better evaluation and leading to more reliable results. This technique provides an important set of information, as total porosity, effective porosity, free fluid porosity, fluid type, saturations of the flushed zone, oil viscosity, permeability index, water adsorbed on clays, residual oil calculation, viscosity evaluation, anisotropy, heavy oil, tar sands, carbonate complex lithologies (pore distribution, pore types, pore connectivity and grain sizes), pseudo capillary - pressure curves, producibility, etc. However, NMR technique is costly and, therefore, is not performed on all the wells of an oilfield. Hence, it is important to develop advanced computational models to infer many parameters that it can provide us (Coates et al., 1999).

In the evolution of computational models, artificial intelligence techniques have shown good results in the synthesis of porosity and permeability curves using conventional logs as input (Nikravesh et al., 2003). In this sense, good applications of these techniques have been produced by Ogilvie et al. (2002), Lim \& Kim (2004), Taghavi (2005), Abdulraheem et al. (2007), Ahrimankosh et al. (2010), Labani et al. (2010), Weldu et al. (2010) and Nashawi \& Malallah (2010). Some works developed in our department, related to the Albian carbonates of the Campos Basin, were developed by Gomes (2017), Mureb (2018), Carvalho (2018), Al-Lahham (2018) and Tavares (2018), among others.

Thus, this work consists in combine different artificial intelligence techniques, such as Artificial Neural Network (ANN) and Fuzzy Logic (FL), couple with Simple Average (SA) and Genetic Algorithm (GA), through the softwares MATLAB (2019) and Interactive Petrophysics (LR Senergy, 2019), to create a quantitative correlation between conventional logs and Schlumberger free fluid porosity (CMFF) and the lateral permeability (KSDR) curves derived from NMR log. From the learning acquired by intelligence systems in a test or training well, this correlation was extrapolated to a neighbor or blind test well to verify the reliability of the method.

\section{GEOLOGICAL CONTEXT}

The Campos Basin is one of the most productive oil basins along the Brazilian continental margin, accounting for more than $45 \%$ of national production based on data from 2018. The basin is in Southeastern Brazil, with the approximate position of Oilfield B discussed in this study, displayed in a red rectangle with dashed line in Figure 1. The Albian carbonate reservoirs of Quissamã Formation are productive in this basin, having a typical porosity of $25 \%$ and, a permeability of $25 \mathrm{mD}$ (Bruhn et al., 2003). The sedimentation of this carbonate started in the drift phase at the beginning of Albian with marine deposition (Fig. 2). The depositional model of this oilfield corresponds to a carbonate platform, and, according to Okubo et al. (2015), this depositional model characterizes the sedimentation in a high-energy environment (oolitic and oncolitic grainstones), a moderate-energy environment (oolitic peloidal grainstones and oncolitic bioclastic packstones) and a low-energy environment (peloidal bioclastic packstones and wackestones) (Fig. 3). In this oilfield, two wells, P1 and P2, were used to perform this study. The Well P1 is in the high-energy of the carbonate ramp and, the Well P2 is in the moderate-energy zone (Fig. 4). These reservoirs are heterogeneous and fractured, which results in a generally low recovery factor, complex rock properties and geophysical well data difficult to interpret. Carbonate reservoirs were characterized through a combination study of their geological characteristics, petrophysical properties and geophysical logs, data that provide a fundamental understanding of their geometry and dynamic properties.

\section{MATERIALS AND METHODS}

In the intelligent systems, discussed in this study, the conventional logs of each well were used as input, namely: gamma ray (GR), resistivity laterolog (RLA1), density (RHOZ), neutron porosity (NPOR) and sonic (DTCO) logs. As targets, it was employed Schlumberger-Doll Research (SDR) free fluid porosity (CMFF) and vertical permeability (KSDR), both derived from NMR log (Franco et al., 2011).

Two wells were selected to accomplish this study, a training well, called P1 and a neighbor blind test well, named P2, which cross a carbonate platform with great lithological variations. For Well P1, Figure 5 shows the description of Well P1 in Campos Basin, well logs, track 1: GR, track 10: RLA1, track 11: RHOZ and NPOR, track 14: NMR T2 distribution and geometrical mean cut-off, and track 15: resistivity image. Track 2: depth. Engineering information, track 3: jointer, and, track 7: oil occurrence. Geological information, track 4: cores, track 5: texture, track 6: grain size, and, track 8: facies. Track 9: petrophysical units. Laboratory measurements, track 12: porosity, and, track 13: permeability. The geological section and, the average porosity and permeability, for each section, are also shown. The logs of the Wells P1 and P2 are shown in the Figures 


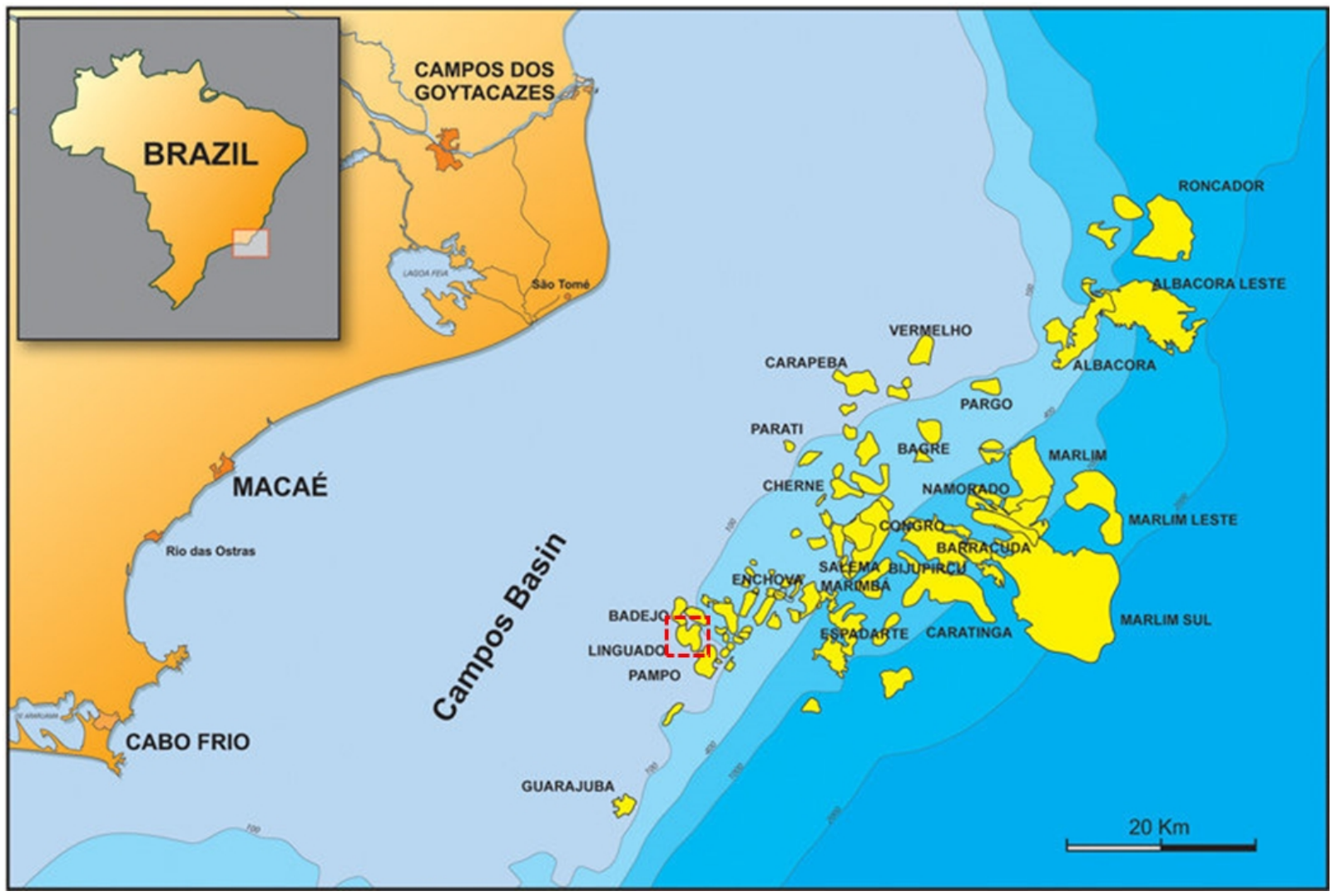

Figure 1 - Location map of the main petroleum fields in the Campos Basin and the studied oilfield in a red rectangle with dashed line (modified from Bruhn et al., 2003).

(A)

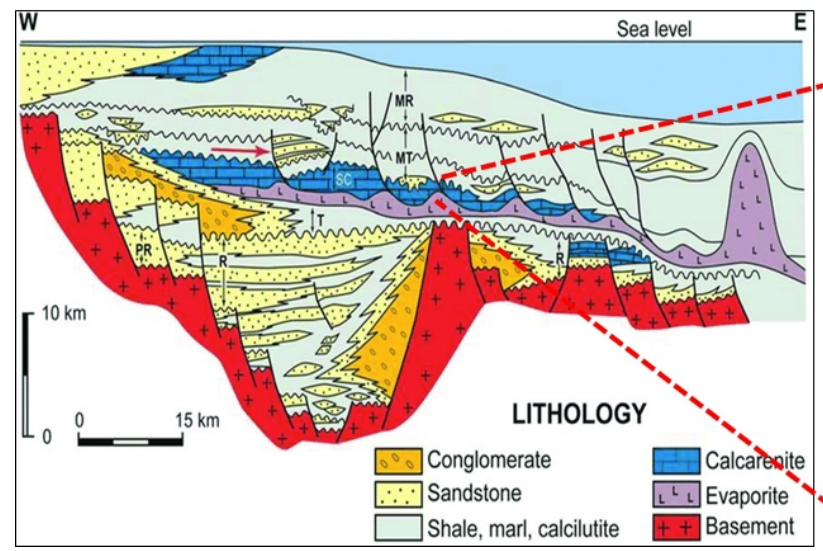

(B)

Figure 2 - (A) Generalized geological section for the Eastern Brazilian continental margin basins. Main mega sequences: PR, pre-rift (which does not occur in the Campos Basin); R, rift; T, transitional (which includes the evaporate section); SC, shallow carbonate; MT, marine transgressive; MR, marine regressive. (B) Lithostratigraphy of this portion of Campos Basin, with the Formations Goitacás (GT), Quissamã (QM), Outeiro (OUT), Imbetiba (IMB) and Namorado (NAM) (modified from Okubo et al., 2015). 


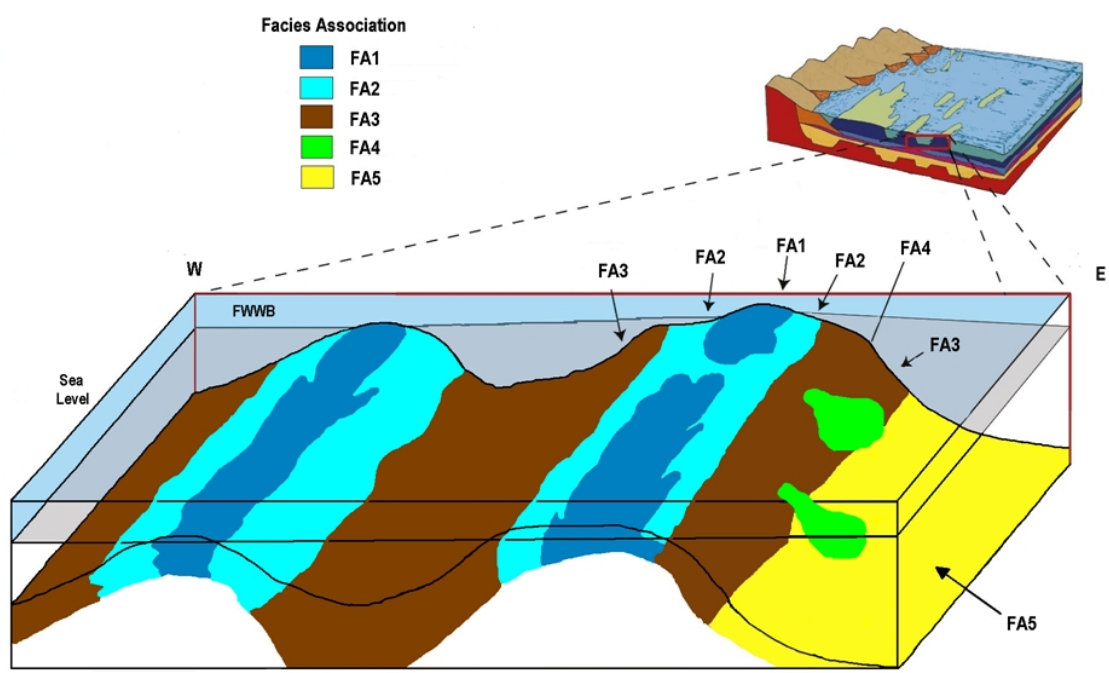

FWWB: fair weather wave base

Figure 3 - Depositional model inferred for the carbonate platform in the Campos Basin during the Albian Age. Facies Association (FA): FA1=oncolitic and oolitic grainstones, FA2=oncolitic peloidal grainstones and ooolitic bioclastic packstones, FA3=wackestones and peloidal bioclastic packstones, FA4=bioclastic packstones and oolitic wackestones/packstones and, FA5=pithonelid wackestones. FWWB=Fair Weather Wave Base. Note the physiographic position of this model compared to the scheme of Guardado et al. (1989) (modified from Okubo et al., 2015).
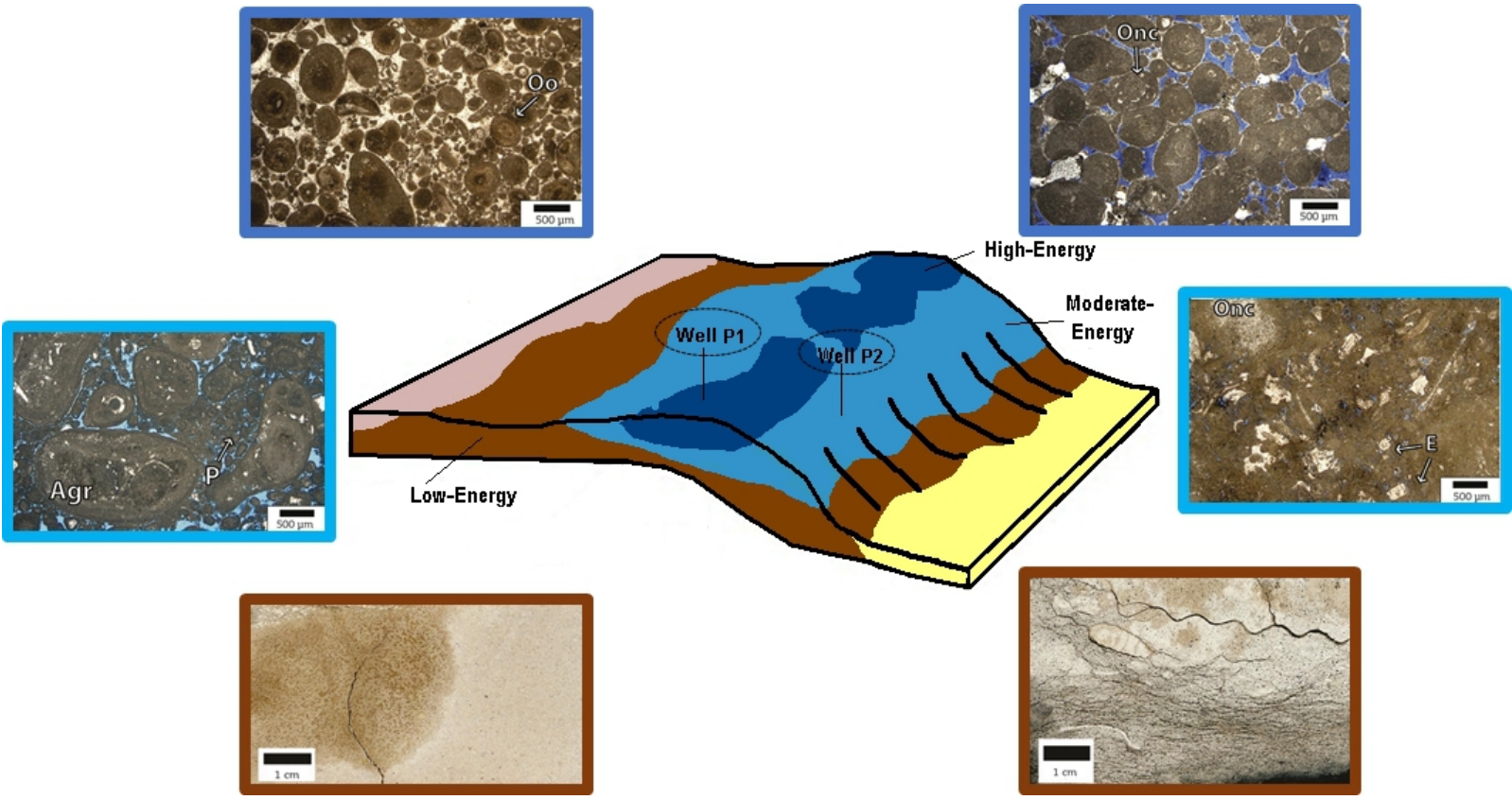

Figure 4 - The generalized location of the Wells P1 and P2 on the carbonate ramp depositional model with representative "depositional energy" designations based on characteristic lithofacies. The photomicrographs from plug samples of each lithofacies and their associated energy zone: oolitic and oncolitic grainstones of the high-energy zone (dark blue), oncolitic peloidal grainstones and oncolitic bioclastic packstones of the moderate-energy zone (light blue), and peloidal bioclastic packstones and wackestones of the low-energy zone (brown) (modified from Okubo et al., 2015). 


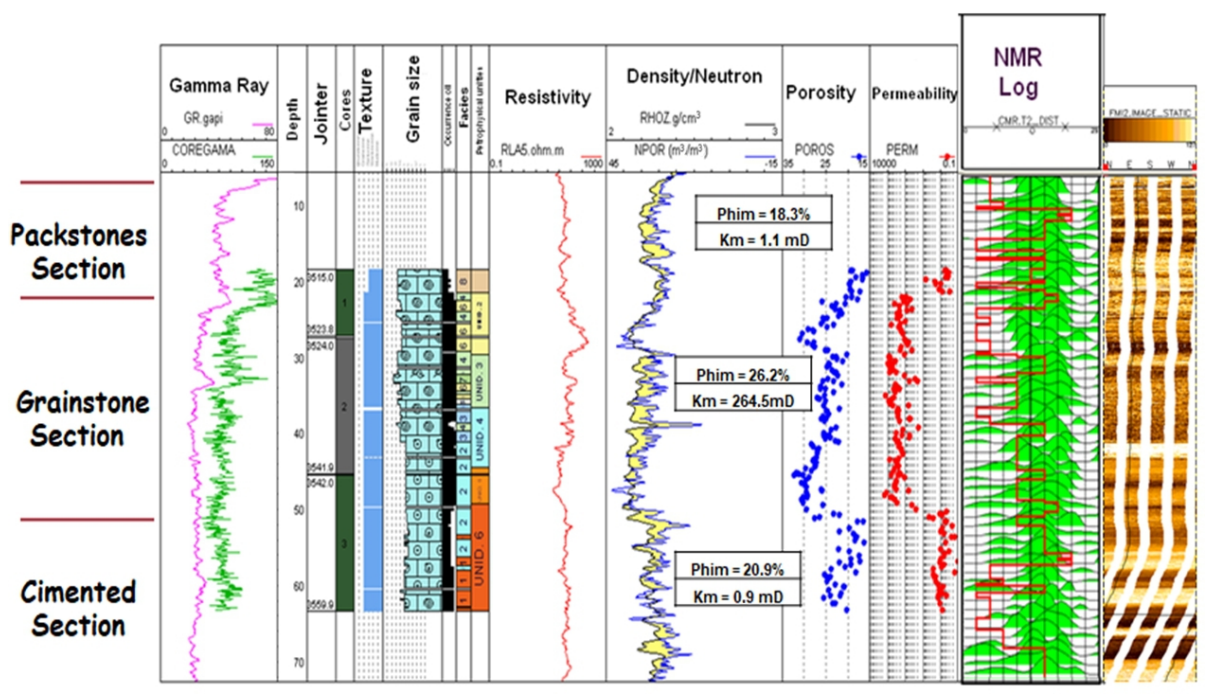

Figure 5 - Description of Well P1 in Campos Basin. Well logs, track 1: GR, track 10: RLA1, track 11: RHOZ and NPOR, track 14: NMR T2 distribution and geometrical mean cut-off, and track 15: resistivity image. Track 2: depth. Engineering information, track 3: jointer, and, track 7: oil occurrence. Geological information, track 4: cores, track 5: texture, track 6: grain size, and, track 8: facies. Track 9: petrophysical units. Laboratory measurements, track 12: porosity, and, track 13: permeability. The geological section and, the average porosity and permeability, for each section, are also shown.

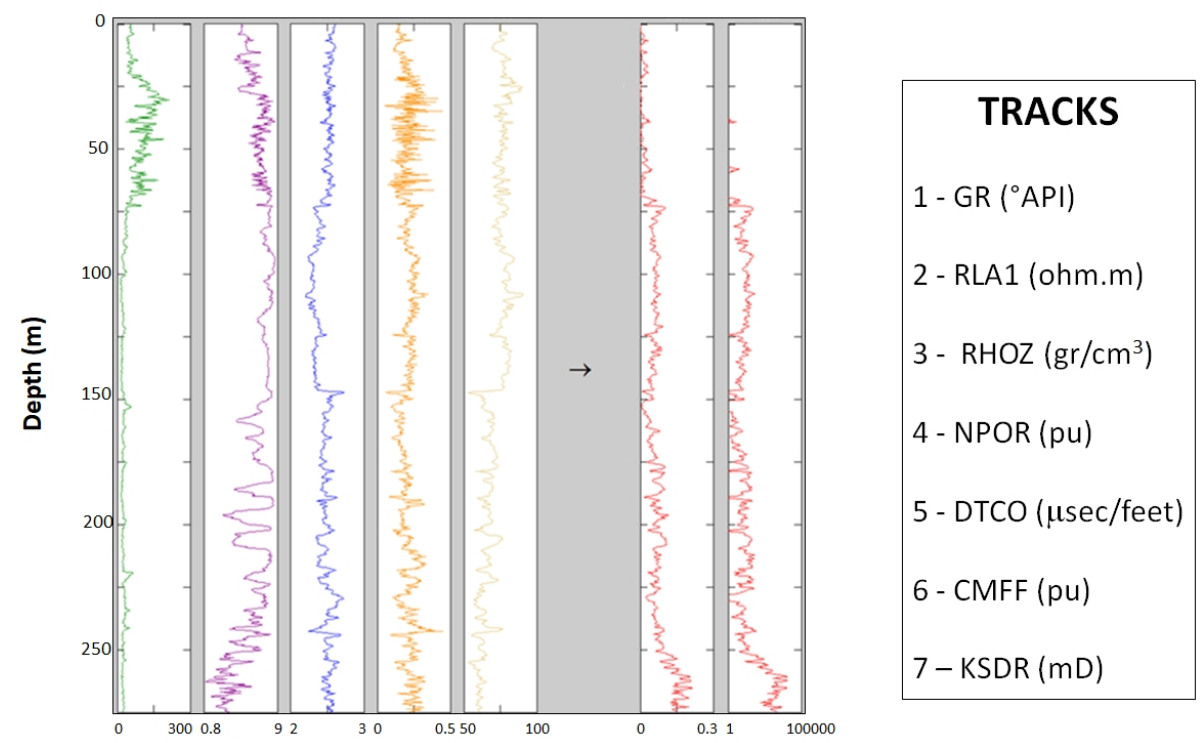

Figure 6 - Well P1 in Campos Basin. Tracks 1 to 5: gamma ray (GR), resistivity laterolog (RLA1), density (RHOZ), neutron porosity (NPOR) and sonic (DTCO) conventional logs; track 6: Schlumberger free fluid porosity (CMFF); track 7: Schlumberger vertical permeability (KSDR); both derived from NMR log.

6 and 7 show GR (track 1), RLA1 (track 2), RHOZ (track 3), NPOR (track 4) and DTCO (track 5) logs; the Schlumberger free fluid porosity (CMFF) in track 6; and, the Schlumberger vertical permeability (KSDR) in track 7.
This work combines different artificial intelligence techniques, such as Artificial Neural Network (ANN) and Fuzzy Logic (FL), coupled with a Simple Average (SA) and the Genetic Algorithm (GA) systems. The estimates of CMFF and KSDR 


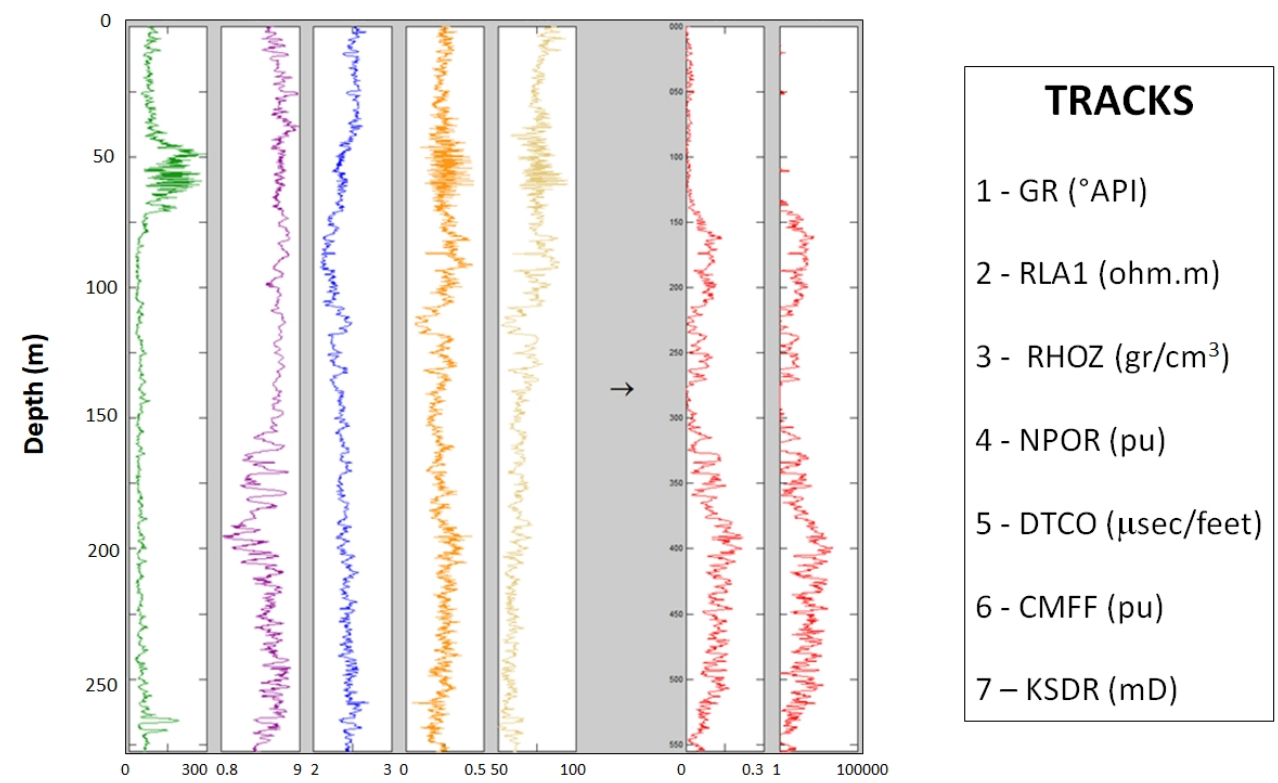

Figure 7 - Well P2 in Campos Basin. Tracks 1 to 5: gamma ray (GR), resistivity laterolog (RLA1), density (RHOZ), neutron porosity (NPOR) and sonic (DTCO) conventional logs; track 6: Schlumberger free fluid porosity (CMFF); track 7: Schlumberger vertical permeability (KSDR); both derived from NMR log.

were compared with the respective laboratory data to calibrate them (not shown in this article). In the end, the quality of the fit, between the Schlumberger and the intelligent systems estimates, is calculated through the Mean Squared Error (MSE). The basic principles of these approaches are shown below.

In the implementation of the FL system, five linguistic variables were used and considered enough to represent the large variation of the logs (Maximiano \& Carrasquilla, 2011). Each variable was controlled by a triangular membership function and, using the FL toolbox of MATLAB (2019). The best results for this technique were obtained with the Mamdani scheme, which offered better control of membership functions and for carrying out inferences. Figure 7 illustrates the adjustment of the membership functions for RLA1 log input in the range [0.846 8.355].

Due to high variations shown on the logs, it was decided to create several rules that reflected more the combinations between the input logs and output logs. Thus, for CMFF, 288 fuzzy proposals were used, which resulted in an acceptable approximation in the validation process, with no adjustments of membership functions. In the case of KSDR, however, because its variation along the well, estimate was not satisfactory. So, it was decided to divide the log into 3 units of similar variations. For each of these sectors, a FL system was built, using each 77, 85 and 20 rules, respectively.
An ANN has three layers of neurons: an input layer, one hidden and one output (Russell \& Norvig, 2010). To train CMFF was used a toolbox backpropagation neural network (MATLAB, 2019) with five neurons in the hidden layer and one neuron in the output layer. The stopping criterion used was the determination of a maximum value of 500 epochs, or iterations. On the other hand, to train KSDR, ten neurons were used in the hidden layer and one neuron in the output layer, with one thousand epochs as stopping criterion. Many trainings were conducted using more than one hidden layer, and, when this number was increasing, the accuracy of the estimate was better in the Well P1 validation process. However, the accuracy in the extrapolation in Well P2 was low and, for this reason, an ANN with only one layer was great. As neuron activation, the ANN models used, as transfer functions, a hyperbolic tangent function (Eq. 1), in the neurons of hidden layer and, a linear function (Eq. 2), in the neurons of output layer:

$$
\begin{gathered}
\tanh (s)=\frac{2}{\left(1+e^{-2 s}\right)}-1, \\
\operatorname{lin}(s)=s,
\end{gathered}
$$

where $s$ represents the sum calculated for each neuron in each propagation. Figure 8 shows the ANN template used to estimate 


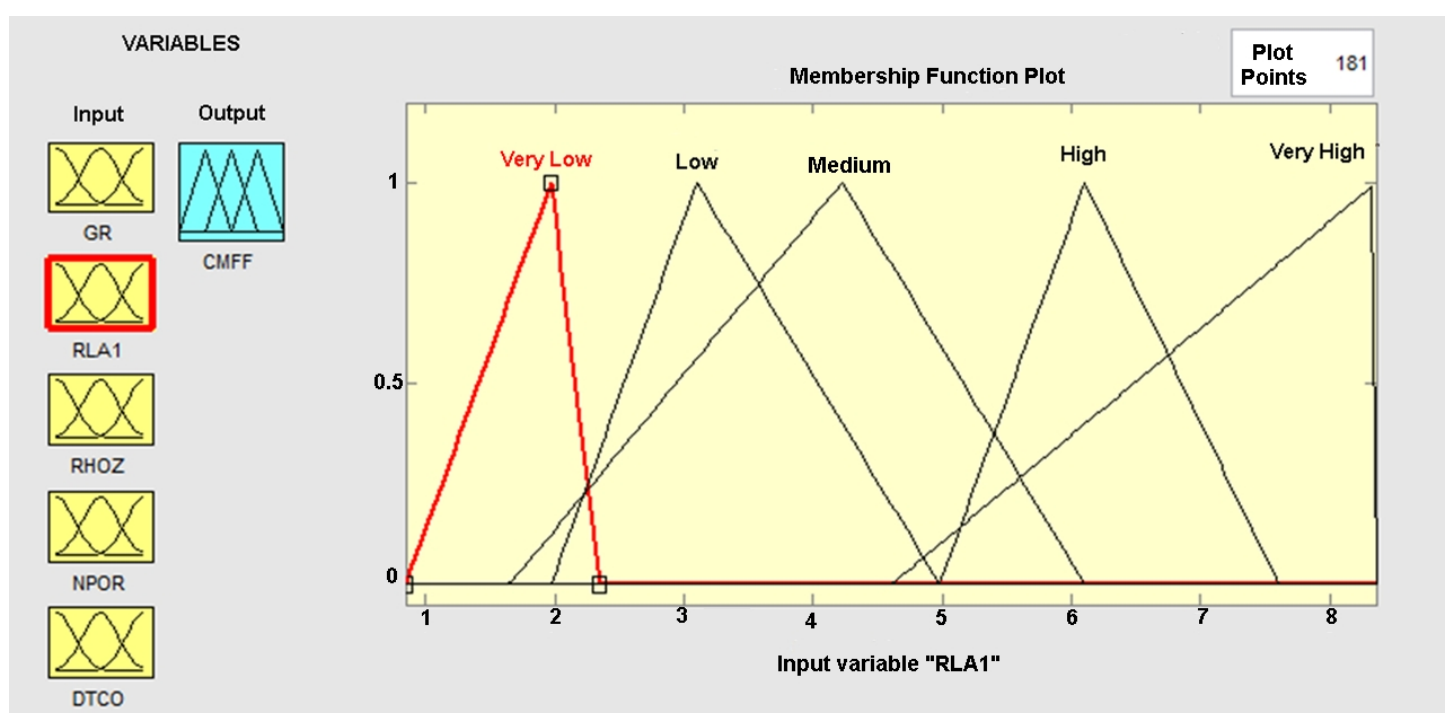

Figure 8 - Final adjustment of the Fuzzy Logic membership functions of the RLA1 resistivity log input to estimate porosity CMFF.

the porosity CMFF. The calculation of a neuron of the hidden layer can be represented by the following function:

$$
n e t_{i}=w_{0 i}+\sum_{j=1}^{5} w_{i j} x_{j}
$$

where $x_{j}$ are the input variables, $w_{i j}$ are the weight factors for each input neurons of hidden layer and $w_{0 i}$ are the bias of each neuron of hidden layer. Considering the neuron of the output layer, the function of calculating the porosity and permeability of a propagation can be represented as follows, respectively:

$$
\begin{aligned}
& \emptyset_{A N N}=f\left[v_{0}+\sum_{i=1}^{5} v_{i} f_{i}\left(\frac{2}{1+e^{-2 n t_{i}}}\right)\right], \\
& k_{A N N}=f\left[v_{0}+\sum_{i=1}^{10} v_{i} f_{i}\left(\frac{2}{1+e^{-2 n e t_{i}}}\right)\right],
\end{aligned}
$$

where $v_{i}$ are the weight factors for each output neurons of the hidden layer and $v_{0}$ is the bias of the neuron of the output layer.

To build the GA approach, FL and ANN estimates were combined by assigning weights for the results of each one. The optimization was performed by minimizing the MSE, searching weights with the best contribution of each log and each scheme (Ogilvie et al., 2002), in the prediction of CMFF and KSDR for training Well P1. GA scheme is based on the summation of FL and ANN results, finding different weights for each approach, as shows in the following equations:

$$
\phi_{G A}=P_{1} \times \phi_{F u z z y}+P_{2} \times \phi_{A N N},
$$

$$
k_{G A}=P_{3} \times k_{F u z z y}+P_{4} \times k_{A N N},
$$

where $P_{1}, P_{2}, P_{3}$ and $P_{4}$ are the weight factors calculated by GA scheme. Figure 9 shows the GA scheme used to estimate the porosity CMFF.

The SA system is based on the elementary arithmetic average of $F L$ and ANN systems described previously. With FL and ANN systems predicting CMFF and KSDR curves of the Well P1, whereby trained, it was proceeded to develop the SA structure which evaluate the result of FL and ANN prediction curves associated in the same ratio. The following equations show how were built the prediction logs of SA system:

$$
\begin{gathered}
\phi_{\text {Mean }}=0.5 \times \phi_{\text {Fuzzy }}+0.5 \times \phi_{A N N}, \\
k_{\text {Mean }}=0.5 \times k_{\text {Fuzzy }}+0.5 \times k_{A N N},
\end{gathered}
$$

in which the values $\phi_{F u z z y}, k_{F u z z y}, \phi_{A N N}$ and $k_{A N N}$ correspond, respectively, to the porosity and permeability of FL and ANN estimates.

The validation process consisted in evaluating the intelligent model of learning, which was constructed and applied using conventional logs as input and CMFF and KSDR curves as output in the training or test Well P1. After this validation, an extrapolation process was executed to estimate CMFF and KSDR output curves of the neighbor Well P2, using as input its own conventional logs.

To evaluate the approximation of the curves generated by the intelligent systems with the target curves of Schlumberger 


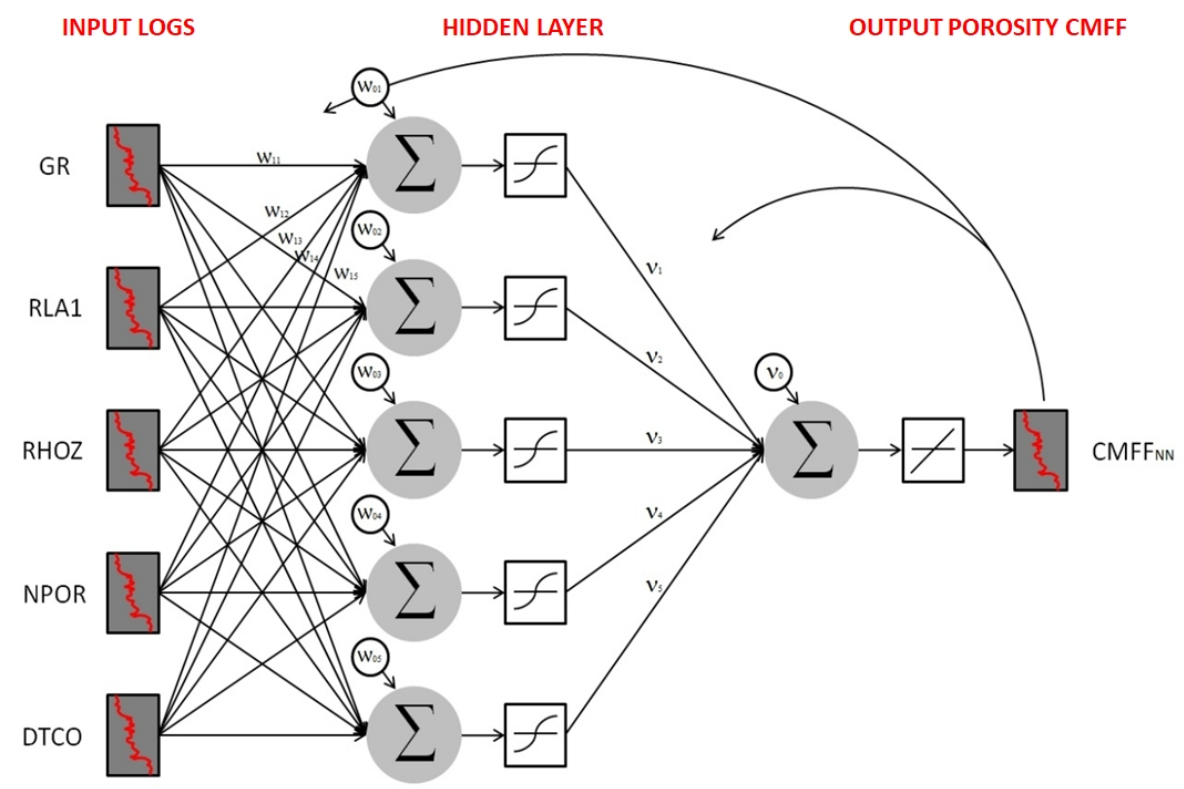

Figure 9 - The Artificial Neural Network scheme used to estimate porosity CMFF.

porosity and permeability, we used the MSE estimation, whose equations can be written as follows:

$$
\begin{aligned}
& M S E_{\phi}=\frac{1}{n} \sum_{i=1}^{n}\left(\phi_{A N N_{i}}-\phi_{i}\right)^{2}, \\
& M S E_{k}=\frac{1}{n} \sum_{i=1}^{n}\left(k_{A N N_{i}}-k_{i}\right)^{2},
\end{aligned}
$$

where $n$ is the number of points of each $\log , \phi_{A N N}$ and $k_{A N N}$ correspond to the porosity and permeability logs of the ANN system and, $\phi_{i}$ and $k_{i}$ are the CMFF and KSDR logs.

\section{RESULTS AND DISCUSSIONS}

Figures 10 and 11 show, respectively, the validation process for CMFF and KSDR in the training Well P1, where the tracks, from left to right, show the estimates for FL, ANN, SM and GA. In these figures, despite simulated curves (blue) do not fit the CMFF and KSDR (red) in the bottom of the well, they were able to identify a peak in the packstones zone, which may be related to the presence of vugs or an aquifer. This could be clarified with the resistive or acoustic well images, but we do not rely on them in the dataset. The GA gave the following weights to the FL and ANN curves for porosity:

$$
\phi_{G A}=0.18900 \times \phi_{F u z z y}+0.83224 \times \phi_{A N N},
$$

where the $\phi_{G A}$ value corresponds to the log calculated by GA. The weights were calculated by the Genetic Algorithm and are shown in the following equation for permeability:

$$
k_{G A}=0.11290 \times k_{F u z z y}+0.84600 \times k_{A N N} .
$$

Comparing the different estimates, it was observed that ANN behaved better than FL one. On the other hand, SA approach, although used benefits of ANN estimate, was hampered by FL simulation. In the same sense, GA system identified the best combination of FL and ANN approaches, optimizing the fit between the curves. Even among comparisons, FL and ANN approaches obtained acceptable results for CMFF and KSDR curves.

Figures 12 and 13 show, respectively, the extrapolation processes for CMFF and KSDR curves for the neighbor Well P2. In the first 150 meters of these figures, it is possible to observe Iow CMFF and KSDR values, probably caused by an area rich in wackestone, where the estimates for all schemes present values above the real values for both parameters. Although some values are higher than NMR parameters, ANN simulation was able to identify this low CMFF zone. Still in these depths, some negative values for KSDR were estimated, which appear as "square form" in the estimated curves, where this kind of failures are acceptable to represent zones having very low KSDR values. Between 150 to 375 meters, comprising grainstones and half of the cemented grainstones zones, FL and ANN simulations estimate 
- Genetic Algorithm (GA)

- generates a random population,

- assesses the suitability of $\phi_{\mathrm{GA}}$,

$\phi_{\mathrm{GA}}=\mathrm{MSE}\left(\mathrm{W}_{1} * \mathrm{FL}+\mathrm{W}_{2}^{*} \mathrm{ANN}-\phi_{\mathrm{CMFF}}\right)$

- reproduces and selects the "parents",

- crossing - a new generation,

- mutation,

- degree of aptitude.

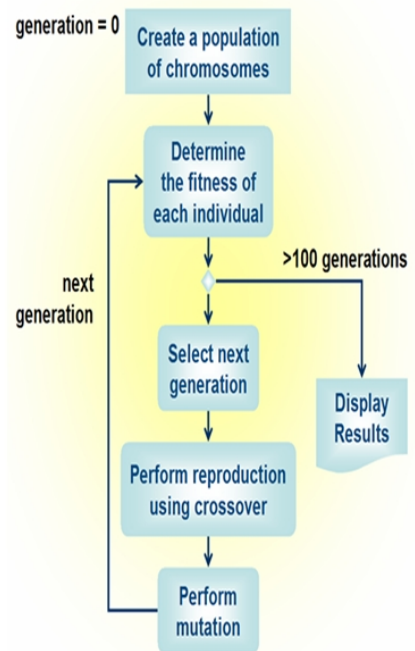

Figure 10 - The Genetic Algorithm scheme used to estimate the GA porosity $\left(\phi_{G A}\right)$. GA is Genetic Algorithm, MSE is Mean Squared Error, $W_{1}$ and $W_{2}$ are weights, FL is Fuzzy Logic, ANN is Artificial Neural Network, $\phi_{G A}$ is the GA estimated porosity and $\phi_{\mathrm{CMFF}}$ is the Schlumberger free fluid estimated porosity.

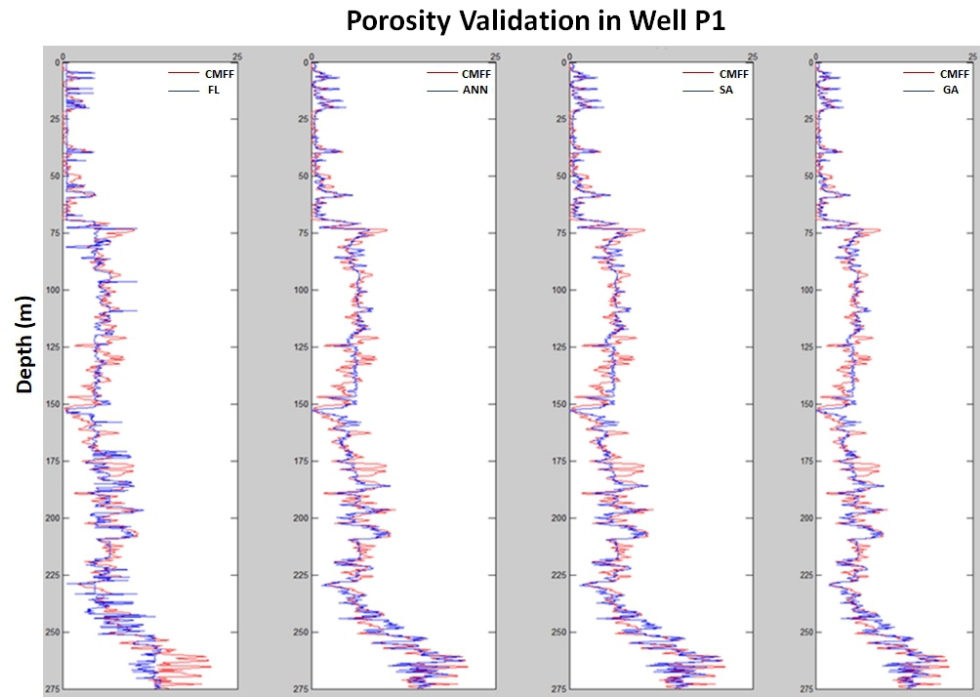

Figure 11 - Porosity validation in Well P1 of Oilfield A in Campos Basin.

the porosity variations in a reasonable manner. Above 375 meters, in packstones zone, ANN estimated CMFF curve with relative accuracy again, stood out over the others. However, FL scheme identified non-existent peaks of high CMFF above NMR values. In the rest of the log, FL estimate did not follow precisely the KSDR curve, but was able to identify the variation between the layers even with a "square form" curve. FL and ANN, as independent systems, identified the variations for both parameters in an acceptable form in neighbor Well P2, remembering always the estimates in training well and the complexity characteristics of carbonate reservoirs. This proves that both systems achieved the same learning for a combination of conventional logs, that is, this region could have higher KSDR values, as recorded in Well P1. Anyway, as the Well P1, ANN estimates in Well P2 functioned better than the FL simulations. In the meantime, through the weights acquired by the GA scheme to estimate CMFF of the Well P1, the system sought to optimize GA estimates of FL and ANN approaches from the Well P2 in a single log. As the assigned 


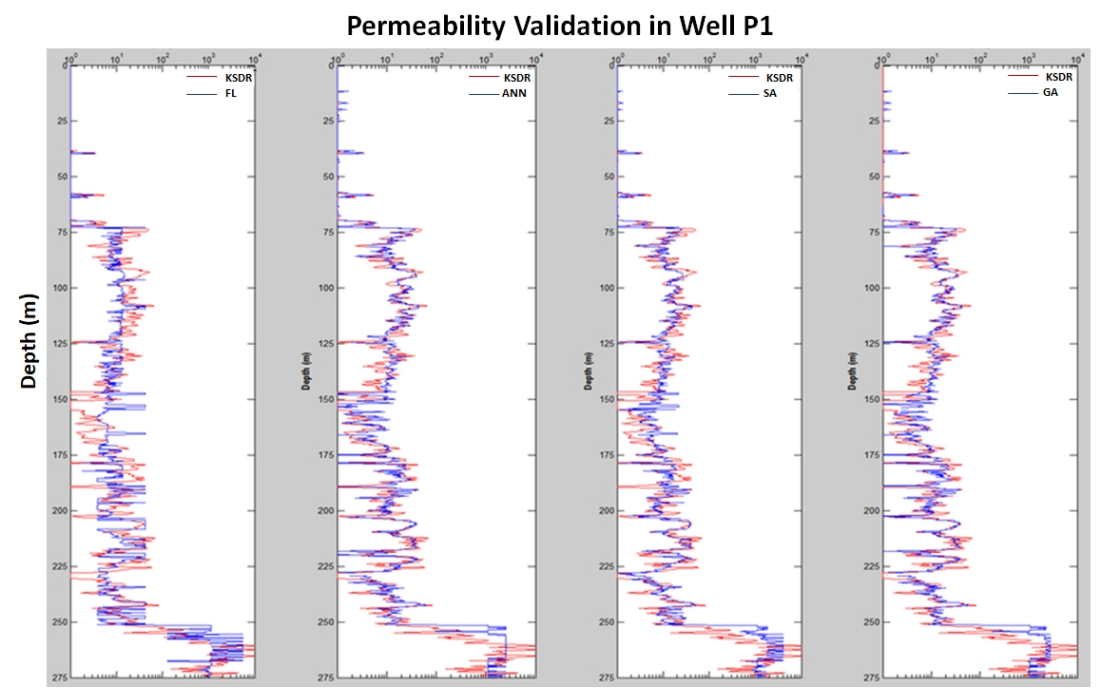

Figure 12 - Permeability validation in Well P1 of Oilfield A in Campos Basin.

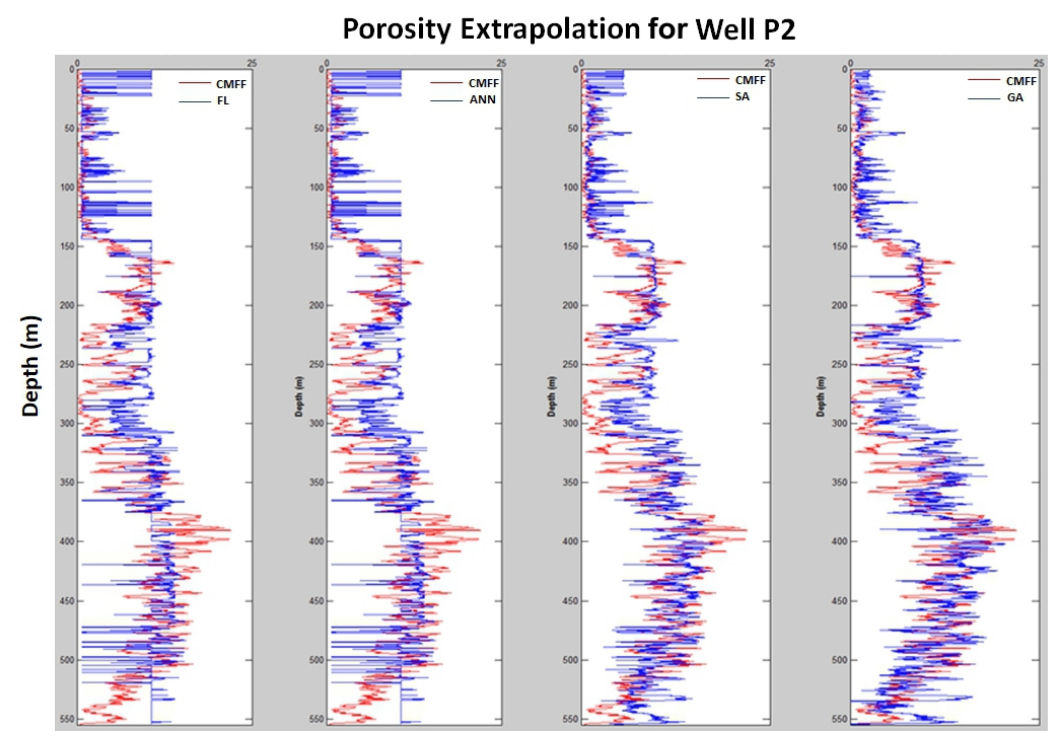

Figure 13 - Porosity extrapolation for Well P2 of Oilfield A in Campos Basin.

weight to ANN estimative is greater than the weight given to FL one, as soon as, GA simulation resembles ANN estimative. Something similar happened with SA scheme.

To compare the efficiency of each approach, it was calculated the MSE of each prediction, for both, the validation process in Well P1, as well as the extrapolation for Well P2. Table 1 shows the errors of the validations of CMFF and KSDR, as well as the classification of each method, according to their best approximation to the original NMR parameter curves. In the case of CMFF, ANN showed an error smaller than FL scheme, with an intermediate result for the SM approach. Although,
GA optimization obtained the best results, using weights to improve the ANN results and best part of FL estimate. In KSDR validation, the classification was equal to CMFF one, in other words, ANN overcame FL, SM approach remained between them and $A G$ achieved again the best result. Despite the GA system have overcome the ANN validation, this improvement was not significant, because ANN obtained excellent results individually, which was reflected directly in GA estimate. On the other hand, Table 2 shows the errors of extrapolations of CMFF - KSDR and the classification of each intelligent system in accordance with the best results. In the case of CMFF, again, the ANN had better 


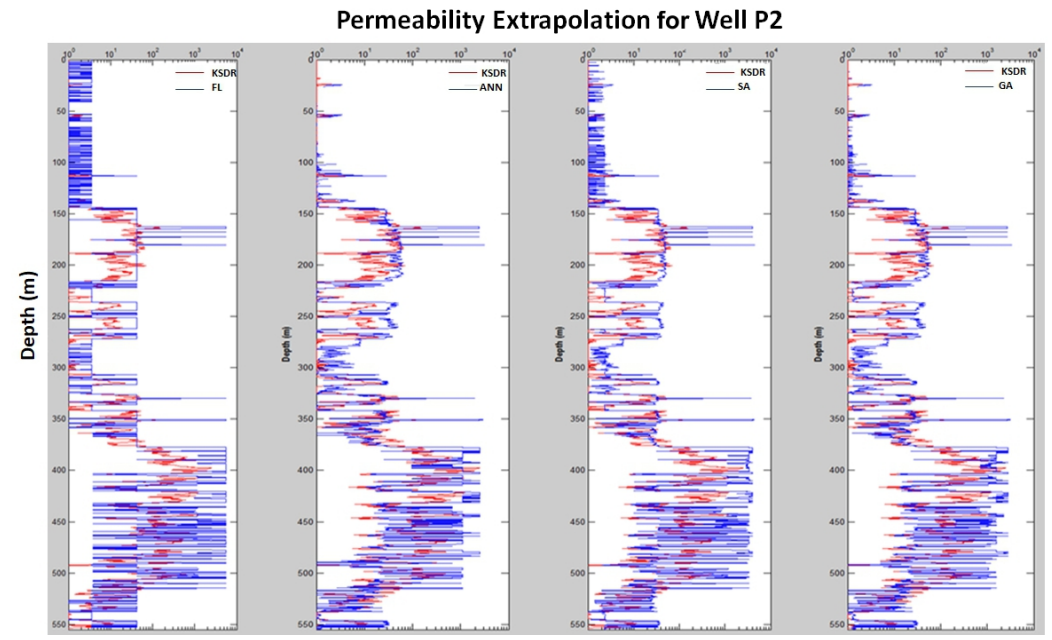

Figure 14 - Permeability extrapolation for Well P2 of Oilfield A in Campos Basin.

Table 1 - Comparison among the validation errors.

\begin{tabular}{|c|c|c|c|c|}
\hline \multirow{2}{*}{ INTELLIGENT SYSTEM } & \multicolumn{2}{|c|}{ POROSITY (pu) } & \multicolumn{2}{c|}{ PERMEABILITY (mD) } \\
\cline { 2 - 5 } & MSE (pu) & Rank & MSE (pu) & Rank \\
\hline Fuzzy Logic (FL) & 0.00035048 & 4 & 715520 & 4 \\
\hline Artificial Neural Network (ANN) & 0.00017897 & 2 & 488170 & 2 \\
\hline Simple Average (SA) & 0.00020668 & 3 & 528991 & 3 \\
\hline Genetic Algorithm (GA) & 0.00017390 & 1 & 485011 & 1 \\
\hline
\end{tabular}

Table 2 - Comparison among the extrapolation errors.

\begin{tabular}{|c|c|c|c|c|}
\hline \multirow{2}{*}{ INTELLIGENT SYSTEM } & \multicolumn{2}{|c|}{ POROSITY (pu) } & \multicolumn{2}{c|}{ PERMEABILITY (mD) } \\
\cline { 2 - 5 } & MSE (pu) & Rank & MSE (pu) & Rank \\
\hline Fuzzy Logic (FL) & 0.00182876 & 4 & 715520 & 4 \\
\hline Artificial Neural Network (ANN) & 0.00126872 & 3 & 488170 & 1 \\
\hline Simple Average (SA) & 0.00123483 & 1 & 528991 & 3 \\
\hline Genetic Algorithm (GA) & 0.00124656 & 2 & 485011 & 2 \\
\hline
\end{tabular}

performance than FL system. SM and GA schemes, through the average calculation and obtained weights, were able to reflect an optimization of $\mathrm{FL}$ and ANN estimates, even this improvement does not represent a significant error reduction compared with the other approaches. In the case of KSDR, ANN had the best accomplishment, followed by GA, SM and, as usual, FL in the last position.

\section{CONCLUSIONS}

In this work, artificial intelligence techniques were used to estimate the free fluid porosity and vertical permeability of the Nuclear Magnetic Resonance log, using as input gamma ray, resistivity, density, neutron porosity and sonic well logs. Four combinations were constructed, using, initially, Fuzzy Logic and Artificial Neural Network in independent schemes, while Simple 
Average and Genetic Algorithm structures sought for optimized solutions. Due to high variation of the logs used, the construction of the Fuzzy Logic algorithm was troublesome in the creation of rules and adjusting the membership functions. These two stages are equivalent to the training phase of Artificial Neural Network. However, while Artificial Neural Network learns alone, Fuzzy Logic needs to be taught step by step. In general, both in the validation as extrapolation, the Artificial Neural Network system has achieved satisfactory results. The training of an artificial intelligence should not be precise in this type of study. After all, the two wells have similar geological standards, but different. The more you train an artificial intelligence for the solution of a given problem, the smaller its capacity for abstraction to solve different problems. In the case of Fuzzy Logic, the more the system is adjusted, the best results are obtained on extrapolation. After all, compared with an Artificial Neural Network, Fuzzy Logic would be a network with a very strong supervision, which would limit the learning of the intelligence only the necessary through greater freedom of the supervisor. The reductions in errors later acquired by Genetic Algorithm scheme and, on extrapolation, by the Simple Average system, do not represent significant improvement over the Artificial Neural Network rule. The Simple Average system is an elementary algorithm with fast simulation and requires no training but is dependent on other structures. As expected, the Genetic Algorithm scheme optimized results of Fuzzy Logic and Artificial Neural Network systems in the validation process of the Well P1. However, considering the estimates of the permeability of the Well P2, the difference of Fuzzy Logic system is so inferior to the Artificial Neural Network that harmed the Genetic Algorithm results. The results confirmed the efficacy in using these intelligent approaches, working well both individually and jointly, looking for the simulation of Nuclear Magnetic Resonance log parameters. Even though each of these intelligent techniques have achieved different estimates of the Schlumberger free fluid porosity and vertical permeability, the results were satisfactory, in both validation and extrapolation processes. However, the results show that to implement the process exposed in this work, Fuzzy Logic method would not be necessary to use it, because it always showed worse results than Artificial Neural Network, which proved more independent and easier to run the simulation, without the necessity choose membership functions. As the Simple Average and Genetic Algorithm schemes worked only as optimizers of Fuzzy Logic and Artificial Neural Network estimates, only the use of the Artificial Neural Network approach would be enough to make the simulations developed in this article. Finally, it is recommended, for future work, to increase the number of correlation wells used to estimate porosity and permeability and thus distribute the weight of each parameter in Artificial Neural Network and Fuzzy Logic trainings. This is expected to reduce errors associated with profiling operations and well instability problems (enlargements) that may be mislabeled to geological issues.

\section{ACKNOWLEDGEMENTS}

The authors would like to thank ANP/Petrobras for the dataset, LR Senergy for assign to us an academic license of Interactive Petrophysics (IP) software, CAPES for the scholarship to Victor Briones and LENEP/UENF for the computing infrastructure.

\section{REFERENCES}

ABDULRAHEEM A, SABAKHI E, AHMED M, VANTALA A, RAHARJA I \& KORVIN G. 2007. Estimation of permeability from wireline logs in a Middle Eastern carbonate reservoir using Fuzzy Logic. In: SPE Middle East Oil and Gas Show and Conference. Manama, Bahrain, SPE. 1: p. $11-14$.

AHRIMANKOSH M, KASIRI N \& MIRKALAEI S. 2010. Porosity and permeability prediction using Artificial Neural Network based on flow zone index in an Iranian heterogeneous carbonate reservoir. In: 14th International Oil, Gas \& Petrochemical Congress. Narmak, Tehran, Research Institute of Petroleum Industry.

AL-LAHHAM M. 2018. Permeability of carbonate reservoirs of the lower Albian determined with artificial intelligence techniques. Master Dissertation. UENF/CCT/LENEP, Macaé, RJ, Brazil. 144 pp.

BRUHN C, GOMES J, LUCCHESE C \& JOHANN P. 2003. Campos Basin: Reservoir characterization and management - Historical overview and future challenges. In: Offshore Technology Conference. Houston, Texas. OTC. paper OTC-15220, $14 \mathrm{pp}$.

CARVALHO L. 2018. Simulation of the sonic logs in wells of the Campos and Santos Basins. Master Dissertation, UENF/CCT/LENEP, Macaé, RJ, Brazil. 70 pp. [In Portuguese].

COATES G, XIAO L \& PRAMMER M. 1999. NMR Logging: principles \& applications. Houston: Halliburton Energy Services. 234 pp.

FRANCO N, SCHUAB F \& NOCCHI G. 2011. Study to determine T2 cut-offs by integrating the T2 distribution of the Nuclear Magnetic Resonance log with the pore throat distribution of the capillary pressure test by mercury injection. Report of the Project "Analysis of reservoir data". Petrobras/LENEP-UENF/BioRio Foundation Agreement, Macaé, RJ, Brazil. 213 pp. [In Portuguese].

GOMES R. 2017. Comparative study of the permeability estimates of a Campos Basin carbonate reservoir obtained through machine learning 
methods. Master Dissertation, UENF/CCT/LENEP, Macaé, RJ, Brazil. 93 pp. [In Portuguese].

LABANI M, KADKHODAIE-ILKHCHI A \& SALAHSHOOR K. 2010. Estimation of NMR log parameters from conventional well log data using a committee machine with intelligent systems: a case study from the Iranian part of the South Pars gas field, Persian Gulf Basin. Journal of Petroleum Science and Engineering, 72: 175-185.

LIM J \& KIM J. 2004. Reservoir porosity and permeability estimation from well logs using Fuzzy Logic and Neural Network. In: SPE Asia Pacific Oil and Gas Conference. Perth, Australia, Society of Petroleum Engineers. n. 88476, 1: 18-20.

LR SENERGY. 2019. Interactive Petrophysics v4.5, Online user's manual. Available on: <http://www.Ir.org>. Access on: January 10, 2019.

MATLAB. 2019. MATrix LABoratory. Online user's manual. Available on: <https://www.mathworks.com/help/matlab>. Access on: January 10 , 2019.

MUREB P. 2018. Use of multivariate statistics to estimate the permeability of a carbonate reservoir in the Campos Basin. Master Dissertation, UENF/CCT/LENEP, Macaé, RJ, Brazil. 68 pp. [In Portuguese].

NASHAWI I \& MALALLAH A. 2010. Permeability prediction from wireline well logs using fuzzy logic and discriminant analysis. In: SPE Asia Pacific Oil and Gas Conference and Exhibition. Brisbane, Australia, SPE. 1: $18-20$.
NIKRAVESH M, AMINZADEH F \& ZADEH L. 2003. Soft computing and intelligent data analysis in oil exploration. Elsevier, Amsterdam. 754 pp.

OGILVIE S, CUDDY S, LINDSAY C \& HURST A. 2002. Novel methods of permeability prediction from NMR tool data. DIALOG Magazine, London Petrophysical Society. 1: 1-14.

OKUBO J, LYKAWKA R, WARREN L, FAVORETO J \& DIAS-BRITO D. 2015. Depositional, diagenetic and stratigraphic aspects of Macaé Group carbonates (Albian): example from an oilfield from Campos Basin. Brazilian Journal of Geology, 45(2): 243-258.

RUSSELL S \& NORVIG P. 2010. Artificial Intelligence. 3rd. ed., Prentice Hall, Upper Saddle River, New Jersey. 1151 pp.

TAGHAVI A. 2005. Improved permeability estimation through use of Fuzzy Logic in a carbonate reservoir from Southwest Iran. In: SPE Middle East Oil and Gas Show and Conference. Kingdom of Bahrain, SPE. 1: 12-15.

TAVARES M. 2018. Lithofacies, electrofacies and petrofacies in the characterization of an Albian carbonate reservoir using data mining and artificial intelligence. PhD Thesis, UENF/CCT/LENEP, Macaé, RJ, Brazil. $122 \mathrm{pp}$.

WELDU T, GHEDAN S \& AL-FARISI 0. 2010. Hybrid Al and conventional empirical model for improved prediction of log-derived permeability of heterogeneous carbonate reservoir. In: SPE Production and Operations Conference and Exhibition. Tunis, Tunisia, SPE. 1: 8-10.

Recebido em 26 setembro, 2018 / Aceito em 25 junho, 2019

Received on September 26, 2018 / Accepted on June 25, 2019 